ait point of view. All that is now being done in pottery manufacture, all that has lately been achieved in the way of progress; has been here illustrated. An examination, even a rapid one, shows at once how far in advance of other countries England and France are.

Leaving all strictly art questions out of consideration, it is instructive to notice how the technical processes of manufacture impose limits on an artist's scope, and how these scopes have been widened by recent discoveries. It is not intended in this short note to do more than allude to the more important of these, and before doing so it is worth while mentioning that for domestic purposes English earthenware is still unapproached,

The pâte-sur-pâte decoration, so largely used in England and in France, is a good illustration of how a process in itself confines the artist's power within certain limits.

The nature of the ornamentation consists in applying by the brush, and modelling with tools, raised decorations of "paste," which is often, for the sake of artistic effect, in high relief. The paste is of much the same composition as the body on which it is applied, and requires a similar temperature to convert it into China, i.e., $\mathrm{r}, 800^{\circ}$ C. The colours which can be used for staining this paste must therefore also be capable of being produced at this heat, and the result is an entirely new range of ceramic colours. It is fortunate for the success of this style of decoration that the colours obtained are harmonious, of a subdued tone. They are quite unlike any tijat can be produced at a lorrer heat. Apart from the arrist's maripulation, which may vary much in delicacy, the general effect of the production is almost vholly the matural result of the process, and is therefore not due entircly to the artist.

Another and distinct application of raised decoration is very largely represented in the French court. It was first used at Bourg-la-Reine some ten years ago, and is now made in many other localities. It consists of painting in clay on earthenware with pallet and brush in various gradations of relief, somewhat like impasto. The heat for firing is comparatively moderate, and the range of colours that can be employed is very wide.

The difficulties of painting under glaze are by degrees being overcome, and one manufacturer has, for the first time, produced gilding zuder glaze. The coloured glazes shown are rich and brilliant, and are well worth the particular notice of those who have paid attention to their production.

The organisation of the Sèvres manufactory and the fact that it is under the direction of a chemist of repute lead to expectations of discovery resulting from the research here carried out. And as a fact discoveries of no small value have been made of late years. Besides such discoveries as of compounds yielding new colours, there are some which take rank as new processes.

For example, the late Francois Richard, an artist on the staff of the manufactory, found that a large proportion of the enamel colours can be made which will bear a temperature of $600^{\circ} \mathrm{C}$ - - a higher temperature than has been hitherto supposed possible. This higher temperature now employed fuses and softens the glaze; the'colours painted on it blend with it so that, on cooling, there is produced that softness and brilliancy hitherto characteristic of pâte-tendre decoration. This process has been named the demi-grand felt. A great benefit arising from this discovery is that many vases damaged in firing, which would formerly have been abandoned, can now be preserved, as the accidents which so often happen in firing can be repaired. Defects in glaze and colour can be concealed, as, during an exposure to this demi-grand $f c u$, they are at melting-point, and new glaze, when added, becomes so fused that no line of junction is visible. This process also gets over a difficulty that had long been felt in decorating kaolin, or pâte-dur, china, with a pleasing result, as the colours were always crude and harsh, being on the glaze. When a soft effect was required recourse was laad to the less durable and more costly patie-tendre as a body on which to paint.

A new method for decorating porcelain where gold alone is employed has been invented by M. Réjoux. Formerly, when porcelain was decorated with gilding alone, the ornamentation was limited to the production of a pattern by the greater or less relief of the gold, and by its being burnished or left dead. Even the thinnest part of the gilding was opaque. No delicate effects could be produced, 2 nd the style was suited rather for an abundant display of : srbaric wealth than for refinement of expression.

The new process enıbles the gilding to be put on so thinly and transparently that the most delicate effects of light and shade can be produced. It is, however, applicable only to vases of gros bleu colour, that is, to vases coloured with oxide of cobalt. Upon this ground the pattern is drawn with a pigment composed of oxide of aluminium. This is then subjected to a firing which fuses the oxides together, and a brown surface results. This surface is found to be more suitable than any other known for the reception of the gold paste, which can be laid on in a thin film, and then, further, by subsequent removal, can be made to give great transparency. This property of the brown surface is not destroyed by being tinted before the gilding, so that it is possible to tint it with different colours which shall show through. A further variation is very frequently obtained by changing the tone of the gold by mixing it with alloys. This admirable effect of transparency has not been produced by any other means, and the first piece made (with many subsequent) is exhibited.

Another of the processes invented at Sèvies is that of enamelling on pâte-tendre body. In this the colours are applied in powder in the same way as in enamelling on metal, and are fused at a very low temperature. They have more body and are more decided than are those produced by the older enamelling process. On some of the vases shown at the Exhibition the white ground seen is not that of the creamy pate-tendre body, but the pearl white of the stanniferous enamel

Other recent improvements which should find a place in a more technical and exhaustive notice have been illustrated at the Exhibition. It may be mentioned that other nations are striving to adapt some of the traditionally recognised styles and their method of manufacture.

We may, in conclusion, refer to a small but important exhibition of porcelain, allant-au-feu, useful for laboratory as well as for domestic use. It is a very good white, thin and hard, and will bear high temperatures if the changes are not too sudden.

\section{SUN-SPOTS, ATMOSPHERIC PRESSURE, AND} THE SUN'S HEAT

$T$ HE question whether the atmospheric pressure varies with the spotted surface of the sun was noticed by me in a paper on the Isobars within the British Isles. I could not, however, find any appearance of a decennial law in the yearly mean pressures: such a relation presented itself however in the varying directions of the isobars (Proc. Roy. Soc., r 877, p. 599). The yearly mean pressures in our latitudes are subject to large irregular variations, and several decennial periods would be requisite before these could be neutralised in the decennial means. As the irregularities are much smaller within the tropics, I did not fail to examine the yearly means for India which were in my possession at the time; and I found their variations very small and apparently without any relation to the decennial period. Mr. F. Chambers's interesting letter to NATURE (vol. xviii. p. 567) has 
induced me to make a more careful study of the Indian observations at present before me.

Mr. C. Chambers had noticed previously the appearance of "a periodicity of very small range, which nearly corresponds in duration with the decennial sun-spot period " "The Meteorology of the Bombay Presidency." London, $1878, \mathrm{p}$. 12). It is obvious, whatever may be the results derived for a single station, that they can have little value if contradicted by those obtained elsewhere. I have shown that from Singapore to Simla the daily mean pressure varies in nearly the same way, the maxima as well as the minima occurring simultaneously or nearly so over all India (Proc. Roy. Soc., 1876, p. 24). Are then the years of maximum and minimum pressure also the same over India? The question has considerable interest independently of the existence of a decennial law. The following table contains the differences $(\Delta B)$ of yearly mean barometric height in thousandths of an inch from the means derived from the whole series of observations at each station. I possess at present unfortunately only an incomplete series for Trevandrum and the variations for I $841-48$, and for $1853-64$ are those from the means for each of these series of years, the barometers having been different. I have also added the differences of yearly mean temperature in tenths of a degree Fahr. from the means for each series of years during which the thermometer preserved the same position. The different series are separated by bars -

\begin{tabular}{|c|c|c|c|c|c|c|c|c|}
\hline \multirow[b]{2}{*}{$\begin{array}{c}\text { Year. } \\
i\end{array}$} & \multicolumn{4}{|c|}{$\Delta \mathrm{B}$} & \multicolumn{4}{|c|}{$\Delta \mathrm{T}$} \\
\hline & 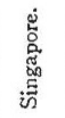 & $\begin{array}{l}\text { 苐是 } \\
\text { 总氙 }\end{array}$ & 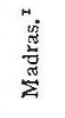 & $\begin{array}{l}\text { ". } \\
\text { हैं } \\
\text { है } \\
\text { है }\end{array}$ & 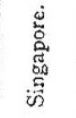 & 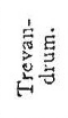 & 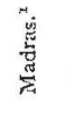 & 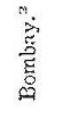 \\
\hline 1841 & & 0 & - & - & -1 & -2 & - & - \\
\hline 1842 & -4 & +6 & -5 & - & +2 & +1 & $+\mathrm{I}$ & - \\
\hline 1843 & -5 & $-I I$ & -7 & - & +3 & & -6 & - \\
\hline 1844 & -3 & $-I$ & -3 & - & -4 & -2 & 0 & - \\
\hline 1845 & +11 & +19 & +19 & - & $+\mathbf{I}$ & +7 & +7 & - \\
\hline I 846 & - & +13 & +14 & $\overline{-u}$ & E & $\begin{array}{l}+5 \\
-5\end{array}$ & $\begin{array}{l}+2 \\
-\quad 2\end{array}$ & -6 \\
\hline I 847 & - & -13 & -8 & $-n$ & - & -8 & & -0 \\
\hline 1848 & - & -9 & -7 & -3 & - & $-I$ & -2 & +2 \\
\hline 1849 & - & - & -23 & -10 & - & - & +2 & 0 \\
\hline 1850 & $\cdots$ & - & -7 & 0 & - & - & -2 & +3 \\
\hline 1851 & - & - & -6 & -12 & - & - & -5 & $-I$ \\
\hline 1852 & - & - & +5 & -3 & - & - & -4 & o \\
\hline 1853 & - & +3 & +6 & +6 & - & - & +2 & +3 \\
\hline 1854 & - & -2 & +2 & -4 & - & - & +4 & +4 \\
\hline 1855 & - & +15 & +20 & +16 & - & - & +5 & +5 \\
\hline 1856 & - & +5 & - & -2 & - & - & - & +3 \\
\hline 1857 & - & - & - & 0 & - & - & - & -3 \\
\hline $18_{58}$ & - & - & - & +4 & - & - & - & $-I$ \\
\hline 3859 & - & +2 & - & +4 & - & - & - & 0 \\
\hline 1860 & - & -6 & - & -4 & 一 & - & - & -2 \\
\hline$x 861$ & - & $-1 I$ & - & $-I I$ & - & - & - & -9 \\
\hline 1862 & - & -19 & - & -25 & 一 & - & - & +4 \\
\hline $186_{3}$ & - & - II & - & -16 & - & 一 & 一 & -4 \\
\hline $\begin{array}{l}1864 \\
1865\end{array}$ & Z & +23 & $\overline{-}$ & $\begin{array}{l}+24 \\
+\quad 3\end{array}$ & 二 & - & 二 & $\begin{array}{r}3 \\
+8\end{array}$ \\
\hline 1866 & - & - & - & $+I_{4}$ & - & - & - & -19 \\
\hline 1867 & - & - & - & +16 & - & - & - & -6 \\
\hline $186 \delta$ & - & - & - & +28 & - & - & - & $-I$ \\
\hline 1869 & - & - & - & +6 & - & - & - & +7 \\
\hline 1870 & - & - & - & - II & $\cdots$ & $\cdots$ & - & -2 \\
\hline 1871 & - & - & - & -3 & - & - & 一 & +9 \\
\hline I 872 & - & - & - & -13 & - & - & - & -3 \\
\hline
\end{tabular}

There is an error of -20 in the mean pressure given in the Madras chservations for 1846 (here corrected)

The variations for Hombay are taken from Mr. C. Chambers's "Mete?sology of the Presidency of Bombay," pp. In and 32 .
An examination of the quantities $\Delta \mathrm{B}$ will show that all the principal deviations from the mean pressures occur in the same years and have the same sign at all the stations. The agreement of the variations for Trevandrum and Bombay in the six years $1859-64$ is also very remarkable.

We see that there was a maximum of pressure in 1845 at the first three stations, a minimum at Madras and Bombay in 1849 (best marked at the former station), a maximum at the last three stations in 1855 ; a minimum in 1862 , and a maximum in 1864 at Trevandrum and Bombay (the latter station showing a maximum also in 1868). These means, then, confirm in a general way for all India the result obtained by Mr. C. Chambers for Bombay, ${ }^{x}$ that on the whole the mean atmospheric pressure is greatest near the epochs of minimum, and least near the epochs of maximum sun-spots, though there is no exact agreement between the two classes of variations from year to year.

And as the maximum pressure in 1855 , shown at all the three stations, is considerably before the epoch of minimum sun-spots, it would be difficult to conclude that the epochs of one phenomenon lag on those of the other.

I consider this result to be one of very great importance. The exactness with which the mean barometric height has been obtained with standard instruments in first-class observatories, and the general agreement of the years of maxima and minima over India, give a weight to it which cannot be extended to an element so variable with locality as the rainfall. Although the barometric variations are not sufficient to explain those of the amount of rainfall (which is so different in different years, and for the same years at the different stations), yet they give a probability to the existence of similar laws in the variations of the meteorological elements which I believe was previously wanting.

Mr. F. Chambers's note was written chiefly with the object of deducing from the barometric means evidence that the emission of solar heat is greatest in years of most sun-spots. He says: "It is well known that in Central Asia the annual variation of the barometric pressure is greater than in any other portion of the globe, and it is universally admitted that this variation is due to the great variation of temperature between summer and winter, the barometer being low when the temperature is high, and vice vers $\hat{a}$. If, therefore, the absolute heat of the sun is subject to considerable variations, we ought to. find the barometric pressure in Central Asia responding to those variations just as it does to the annual variations of temperature; in other words, the summer barometric minimum should be lowest in those years when the sun is hottest, and the winter maximum should be highest in those years when the sun is coldest."

As I do not admit that the annual barometric oscillation is due to variation of temperature, I do not accept the conclusion: for though there is an apparent relation between the two, within certain geographical limits, and under certain local conditions (which are altogether independent of the heat emitted by the sun), there is no evidence that the one is due to the other. The true conclusion is that the local conditions which are favourable to a large oscillation of the monthly mean atmospheric pressure are favourable to a large oscillation of the montbly mean temperature: always within certain geographical limits, for beyond these the relation does not hold.

The subject is, I think, a very interesting one, and merits consideration. The relation of the oscillations of the monthly means will be seen from the ranges in the following table:- 


\begin{tabular}{|c|c|c|c|c|c|}
\hline & \multirow{2}{*}{ Lat. N. } & \multirow{2}{*}{ Long.E. } & \multicolumn{3}{|c|}{ Ranges of Monthly Mieans. ${ }^{\mathrm{T}}$} \\
\hline & & & Barometer. & $\begin{array}{l}\text { Therma- } \\
\text { meter. }\end{array}$ & $\begin{array}{l}\text { Bar. oscilla- } \\
\text { tion f jr } \text { iे }^{\circ} \text {. }\end{array}$ \\
\hline $\begin{array}{lcc}\text { Singapore } & \ldots . & \ldots \\
\text { Trevandrum } & \ldots \\
\text { Madras } & \ldots & \ldots \\
\text { Bambay } & \ldots . & \ldots \\
\text { Pekin } & \ldots & \ldots \\
\text { Catherinenburg } & \ldots\end{array}$ & $\begin{array}{rl}0 & 1 \\
1 & 19 \\
8 & 30 \\
13 & 4 \\
18 & 54 \\
39 & 54 \\
56 & 50\end{array}$ & $\begin{array}{r}104 \\
77 \\
80 \\
73 \\
117 \\
60\end{array}$ & $\begin{array}{l}\text { in. } \\
0.064 \\
0.112 \\
0.299 \\
0.289 \\
0.285 \\
0.777 \\
0.370\end{array}$ & $\begin{array}{l}3: 15 . \\
4 \cdot 8 \\
11 \cdot 8 \\
11 \cdot 4 \\
52 \cdot 8 \\
64.8\end{array}$ & $\begin{array}{l}\text { in. } \\
0^{\circ} 021 \\
0.023 \\
0.025 \\
0^{\circ} 025 \\
0.015 \\
0.005\end{array}$ \\
\hline
\end{tabular}

I have not the means for Calcutta, but they confirm the relation shown for the other Indian stations. At Madras and Bombay the barometric oscillation corresponding to $\mathbf{1}^{\circ} \mathrm{F}$., attains a maximum, it has diminished considerably at Pekin, and at Catherinenburg it cannot be said to exist; for though the minimum pressure occurs near the epoch of maximum temperature, the time of maximun pressure may be said to extend over the seven months, October to April, during which the monthly mean temperature varies $37^{\circ} \mathrm{F}$. Also at Hobarton $\left(42^{\circ} \mathrm{S}\right.$.) the relation does not exist, though the range of monthly mean temperature is nearly $20^{\circ}$.

When we examine the individual cases in India more in detail, several facts present themselves which are opposed to any relation of cause and effect between the two phenomena. Thus, as regards the epochs of maximum of one variation, and minimum of the other, though both show considerable approximation to the solstices, yet there are some marked differences. At Bombay, where the barometric oscillation is greatest for a given oscillation of temperature, the epoch of maximum pressure precedes by nearly a month that of minimum temperature, while the epoch of minimun pressure occurs more than a month after that of maximum temperature. We find also that the relation of increasing oscillation of pressure with increasing oscillation of temperature which holds within certain limits for different places does not hold at the same place. That is to say, years of largest annual variation of monthly mean temperature are not years of largest variation of monthly mean pressure, and in some cases (as at Trevandrum) the range of monthly mean temperature may be nearly twice as great in one year as in another. ${ }^{2}$

No better example, however, of the relation of the two oscillations to local conditions can be given than that presented by the variations at two stations within sixty English miles of each other, Trevandrum within four miles of the sea on the western side of the Ghats, and Pallamcottah on the eastern side, nearly in the centre of the burning plain of Tinnevelly; and about $13^{\prime}$ north of Trevandrum. The monsoon, which commences in the end of April on the western side of the Ghats, is not felt at Pallamcottah; the annual range of temperature is thus much greater than at Trevandrum. The following are the mean ranges at Pallamcottah, derived from three years' observations by Col. W. H. Horsiey, of the Madras Engineers, to whose lindness I owe them. ${ }^{3}$ The

- ${ }^{x}$ From means of five years' observations at Singapore and Catherinenburg, six years at Pekin, twenty-six years at Eombay, eight years at Trevandrums, and fourteen years at Madras.

a. 2 When the twenty-six years' observations at Bombay are placed in two groups, one with the largest, the other with the smallest annual variation of monthly mean temperature, I find the following ranges of the monthly means, derived in each case from the means of thirtean years Pressure.

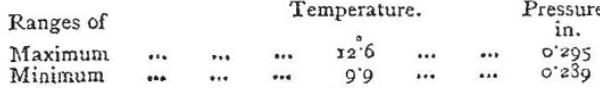

$$
\begin{aligned}
& \begin{array}{lllllll}
\text { Difference } & \ldots & \ldots & \overline{2.7} & \ldots & \ldots & 0.006
\end{array}
\end{aligned}
$$

The difference of ranges of pressure for $2^{0 .} 7$ at Bombay at the rate of 0.025 in. for $x^{\circ}$ should be 0.067 in. The difference of pressure found is in the right direction, but is not one-eleventh of what it should be if the two were related as cause and effect, or even if the two were exact measures of variation of a single cause,

${ }_{3}$ The approximate height of Pallamcottah alowe the sea-level is 125 feet: that of the Trevandrum barometer being 193 fcet.
Trevandrum ranges are placed beside them for comparison:-

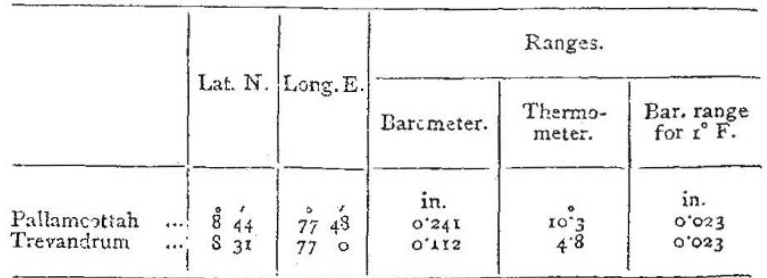

It will be seen that the ranges at Pallamcottah are more than double those at Trevandrum. The consequence of this remarkable fact is that, with an equal mean pressure at the two stations, the monthly mean pressure at Pallamcottah must be 0.065 inches greater in January and 0.065 inches less in June than at Trevandrum, and that the oscillations appear independent of the laws of equilibrium of pressure in gases. ${ }^{x}$

That the higher pressure in January at Pallamcottah does not depend on the lowness of the temperature in that month is proved by the fact that at Trevandrum, sixty miles distant, the mean temperature for January is more than $4^{\circ} \mathrm{F}$. lower, and the pressure, instead of being higher on this account, is really more than half a tenth of an inch of mercury lower than at Pallamcottah for the same level.

The question which is now particularly before us refers to the yearly mean pressures. As the exact teight (above sea-level) and index-erior of Col. Horsley's barometer are unknown to me, and the direction of mean isobars can be determined with any accuracy only from observations with standard instruments, whose heights above the sealevel have been ascertained by levelling, I have employed for their determination observations made at the three observatories of Trevandrum, Madras, and Bombay, which fulfil the requisite conditions. The following are the mean pressures and mean temperatures at the stations; I have added a near approximation to the mean pressure at Singapore. ${ }^{2}$

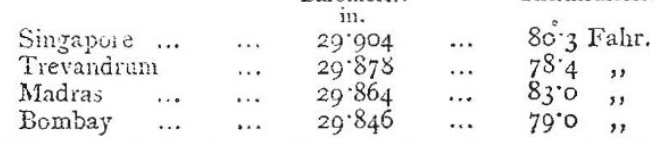

When the latitudes and longitudes given previously are considered, it will be seen that the mean pressure diminishes from the equator at the rate of 0.003 inch for each degree of latitude; and that the yearly mean isobars run parallel to the equator (this conclusion is independent of the mean for Singapore). It will be seen also that the yearly mean isotherms do not lie parallel to the equator, their directions being determined chiefly by local conditions.

As the difference of latitudes of Trevandrum and Pallamcottah is only 13 , the difference of yearly mean pressures should, by the preceding result, not exceed 0 - 1 inches, while the mean temperatures differ by nearly $7^{\circ} \mathrm{Fahr} .^{3}$

We may conclude, then, that, whatever may be the apparent relation of the annual oscillations of pressure ${ }^{x} \mathrm{x}$ do not enter at present into the consideration of the pressure-oscilla tion from 1o A.M. to 4 P.M. which appears to show a similar relation to the temperature-oscillation.

2The mean pressure at Singapore is corrected by $+0^{\circ} 0 z 0 \mathrm{in}$. for recuction to sea-level, a correction which it is believed is near the truth. The mean temperatures have received no reduction to sea.level at three stations as the heights are small, from 20 to 37 feet. That for Trevandrum has been increased by $0^{\circ} 6 \mathrm{~F}$. (height 193 feet) as an approximate reduction to the height of the other stations. The Madras barometric mean is corrected for index-error by $-0^{\circ} 005$. See Introd. Madras Obs. $185 \mathrm{r}-55$.

3 Since by the annual oscillations $x^{\circ}$ Fahr. is equivalent at both stations to $0^{\circ} 023$ inches of merciry, if Mr. Chambers' analogy held, the yearly mean pressures should differ by $7 \times 0^{\circ} 023=0^{\circ} 16 x$ inches. The mean barometric pressure, corrected approximately for height at Pallamcottah, is very nearly the same as at Trcrandrum. This is independent of the conclusions from the directions of the isobars. 
and temperature, this relation does not hold for the vearly means; that is to say, it does not follow that a high yearly mean pressure should indicate a low yearly mean temperature, and vice versâ.

We may, however, arrive at a satisfactory answer to the original question by an examination of the variations of yearly mean temperature at the different stations. It must be remembered that the relation of the oscillations of monthly mean pressure to those of monthly mean temperature are deduced from the variations shown by a thermometer four or five feet from the ground. Does the thermometer at any station, or at a combination of stations, show a high yearly mean temperature with a low yearly mean pressure, and vice versâ? I have given the variations of yearly mean temperature $(\Delta T)$ at different stations, and it requires only a cursory examination of them to see that there is no such relation. There is, however, another fact of very great importance to be deduced from the values of $\Delta \mathrm{T}$, and that is, the very great constancy of the yearly mean temperature at all the stations, in spite of the known considerable variations in the amount of rain and of other meteorological results from year to year.

It may be asked how we can explain the facts which seem to relate the annual oscillations of the mean pressure and mean temperature with the independence of the variations of the yearly means. As an illustration we can suppose that with a strong wind and high tempewature the height of the tide may be increased at a certain port, while a following north wind with low temperatures will diminish the height at low water; we should in such a case, especially if the temperature varied with the force of the wind, have a larger oscillation of the water with a larger oscillation of temperature : we would not, however, attribute the high tide to the greater heat; we can also conceive that the mean temperature might, in the case supposed, vary, but the level of the ocean would remain constant. Other illustrations might be suggested.

The conclusions at which I have arrived are :-

r. That the years of greatest and least mean barometric pressure are probably the same for all India.

2. Therefore, that the apparent relation to the decengial period found by Mr. C. Chambers for Bombay holds for all India.

3. That the annual oscillations of monthly mean pressure and monthly mean temperature have nearly a constant ratio in India.

4. That these oscillations depend on local conditions in the same latitude, at places quite near each other, which are independent of the beat emitted by the sun.

5. That the yearly mean isobars run parallel to the equator in India and are independent of local conditions.

6. That the directions of the yearly mean isotherms vary with the local conditions.

7. That there is no relation between the variations of yearly mean temperature and yearly mean pressure. JOHN ALLAN BROUN

\section{THE SIZE OF THE TIGER}

$\mathrm{IN}$ a work on the tiger, published in $1875,{ }^{1} \mathrm{I}$ made the following remarks in reference to the size of the animal :-

"The size of the tiger varies: some individuals attain great bulk and weight, though they are shorter than others which are of a slighter and more elongated form. The statements as to the length they attain are conflicting and often exaggerated; errors are apt to arise from measurements taken from the skin after it is stretched, when it may be 10 or 12 inches longer than before removal from the body. The tiger should be measured from the nose along the spine to the tip of the tail as he

\footnotetext{
I Royal Tiger of Bengal, pp. 29, $3^{\circ}$.
}

lies dead on the spot whore he fell before the skin is removed. One that is io feet by this measurement is large, and the full-grown male does not often exceed this, though no doubt larger individuals (males) are occasionally seen, and $I$ have been informed by Indian sportsmen of reliability that they have seen and killed tigers over 12 feet in length. The full-grown male Indian tiger, therefore, may be said to be from 9 to 12 feet or 12 feet 2 inches, the tigress from 8 to ro or perhaps in very rare instances II feet in length, the height being from 3 to $3 \frac{1}{2}$, or, rarely, 4 feet at the shoulder."

The point I now especially desire to elucidate as it has been the subject of discussion, but is one that has never yet been satisfactorily settled, is the greatest length the tiger attains.

Jerdon and others say that the average size of a fullgrown male tiger is from 9 to $9 \frac{1}{2}$ feet in length; and Jerdon remarks that he has not seen any authentic account of a tiger that measured more than Io feet and 2 or 3 inches.

I agree with Jerdon that 9 to $9 \frac{1}{2}$ or 10 and 2 or 3 inches are the lengths attained by the majority of tigers met with; but the occasional occurrence of tigers of upward; of Io feet 2 or 3 inches (the authenticity of which is doubted) is attested by the evidence of several competent and reliable observers, who are quite aware that the measurements should be those of the animal as he lies where he fell, and before being despoiled of his skin, and that measurements of the skin after removal are deceptive.

I have taken some pains to ascertain the views of those who are most likely to be well informed on the subject, and I add the results of my own observations during considerable experience in Bengal, Oude, and Nepal; it would seem that the evidence wanted by Jerdon is forthcoming, and that tigers above Io feet 3 inches, ir feet, and even 12 feet, are occasionally met with, and have been accurately neasured.

I may remark that it is very possible that like boars, and other animals, they may differ in size according to locality, food, and other conditions of life; and that such being the case, it is probable that tigers of one province or district may exceed those of another in size. Indeed I am inclined to believe that such is the case, and that therefore those who contend for the larger may be equally right with those who maintain the smaller measurements. I am rather inclined to agree with $\mathrm{Mr}$. C. Shillingford, who suggests the possible progressive degeneration of the tiger; what, certainly, according to some, obtains in the case of stags in the continuously over-shot deer forests of Scotland, may also be going on in the tiger of the much-bunted jungles of India. However this is a mere suggestion, but be it as it may, the inches of the big tiger are, I think, an ascertained fact, for it can hardly be maintained that the authorities who rouch for it are either mistaken or misinformed, or that they do not know how to measure a tiger accurately.

Sir G. Yule, K.C.S.I., Bengal Civil Service, says : "I never had the luck to fall in with a 12 -foot tiger; I I feet odd inches I have killed twice or thrice. I have heard once, at least, of a 12 -foot fellow fairly measured, and I cannot see why there should be any doubt as to the occasional occurrence of such exceptions to the general rule."

Col. George Boileau, Bengal army, says he killed a tiger at Mutearah, in Oude, that was well over 12 feet. He writes:- "I can speak positively as to the size of the tiger-his length was well over i2 feet before the skin was removed. He was, of course, quite an exceptional size, and unequalled, so far as my own experience goes, which extended over seventeen years of constant hunting after the species. My own experience of the ssize of tigers is that, in the female, the size runs from 8 feet to $9 \frac{1}{2}$ feet-the latter exceptionally large; in the male, from 9 feet to II feet; a well-grown adult tiger is 